\section{Isolated hypomagnesaemia presenting as focal seizures in diabetes mellitus}

Hypomagnesaemia is a well known association of diabetes mellitus; it is often asymptomatic but may manifest as tremor, tetany, delirium, hallucinations, or, when severe, generalised seizures. In such instances it is usually associated with hypocalcaemia. ${ }^{1}$ We report on a diabetic patient with severe hypomagnesaemia but normocalcaemia who developed focal seizures that proved refractory to conventional anticonvulsant treatment but were abolished when the serum magnesium concentration was corrected.

\section{Case report}

A 69 year old housewife presented with a three day history of headache and confusion. For 12 years she had suffered from non-insulin dependent diabetes, rheumatoid arthritis, and migraine. There was no history of epileptic fits or transient ischaemic attacks. She was taking glibenclamide, prednisolone, and frusemide.

On examination she was obtunded with left homonymous hemianopia and left sensory inattention. On the day of admission she suffered at least 12 episodes of involuntary head and eye turning (mainly to the left), with associated periods of absence lasting up to two minutes; her husband confirmed that these attacks had started only two days earlier. Investigations showed blood glucose concentration $14.7 \mathrm{mmol} / \mathrm{l}\left(265 \mathrm{mg} / 100 \mathrm{ml}\right.$ ), haemoglobin $\mathrm{A}_{\mathrm{Ic}} 18.3 \%$ (normal range $5-8 \%$ ), corrected plasma calcium $2 \cdot 25 \mathrm{mmol} / \mathbf{l}(9 \cdot 0 \mathrm{mg} / 100 \mathrm{ml}$; normal range $2 \cdot 20-2 \cdot 62$ $\mathrm{mmol} / 1(8 \cdot 8-10 \cdot 5 \mathrm{mg} / 100 \mathrm{ml})$, plasma phosphate $1.03 \mathrm{mmol} / \mathrm{l}(3 \cdot 1 \mathrm{mg} / 100 \mathrm{ml})$, and plasma potassium $3.8 \mathrm{mmol}(\mathrm{mEq}) / \mathrm{l}$. Plasma urea, sodium, and bicarbonate concentrations were normal, as were cardiac enzyme activities. A computed tomogram of the brain was normal, an electroencephalogram showed epileptic activity in the right hemisphere, and her cerebrospinal fluid was normal except for a slightly increased protein concentration $(0.7 \mathrm{~g} / \mathrm{l})$.

A parieto-occipital infarct with associated focal fits was diagnosed initially. Despite control of her blood glucose concentration with an insulin infusion and phenytoin (a loading dose of $1 \mathrm{~g}$ in the first 24 hours followed by $300 \mathrm{mg}$ daily) she continued to fit every four hours. Forty eight hours after admission her serum magnesium concentration was $0.29 \mathrm{mmol} / 1(0.7 \mathrm{mg} / 100 \mathrm{ml})$, and this was verified on four successive occasions within 24 hours (normal range $0 \cdot 7 \cdot 1 \cdot 0 \mathrm{mmol} / 1$ $(1 \cdot 7-2 \cdot 4 \mathrm{mg} / 100 \mathrm{ml})$ ). Magnesium sulphate $3 \mathrm{~g}$ was infused over four hours, and within 12 hours her fits had become less frequent. They had stopped altogether by 30 hours, after a further infusion of $2 \mathrm{~g}$ (figure). Over the next four days her

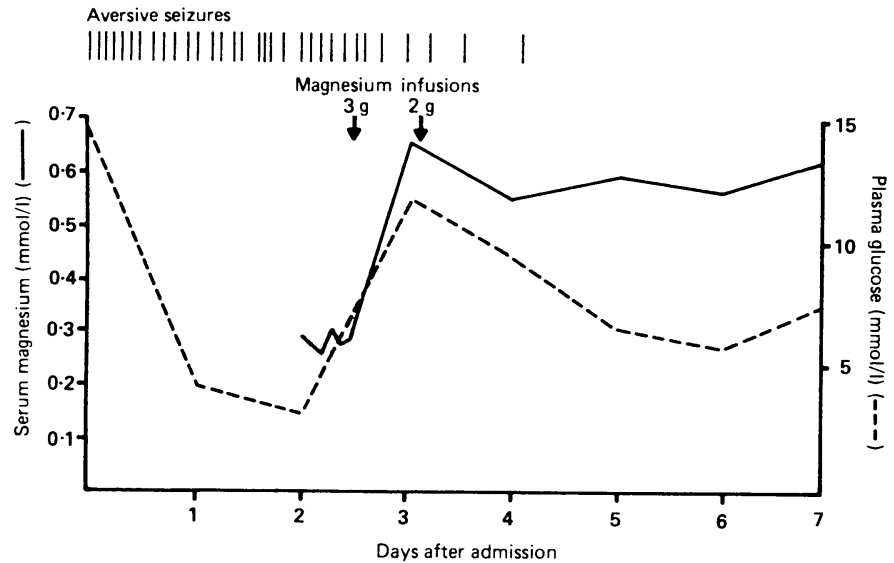

Aversive seizures and magnesium sulphate infusions in relation to serum magnesium and plasma glucose concentrations.

Conversion: SI to traditional units_Serum magnesium: $1 \mathrm{mmol} / \mathrm{l} \approx 2 \cdot 4 \mathrm{mg} / 100$ $\mathrm{ml}$. Plasma glucose: $1 \mathrm{mmol} / \mathrm{l} \approx 18 \mathrm{mg} / 100 \mathrm{ml}$.

neurological signs resolved completely, by which time the serum magnesium concentration had become stable at $0.63 \mathrm{mmol} / 1(1.5 \mathrm{mg} / 100 \mathrm{ml})$. Neither a repeat computed tomogram nor a nuclear magnetic resonance scan of the brain showed any evidence of cerebral infarction. She had no further fits after discharge, and anticonvulsants were stopped after six months.

\section{Comment}

Mild hypomagnesaemia is common in diabetes mellitus. It may occur in a quarter of diabetic outpatients, ${ }^{2}$ and plasma magnesium concentration varies inversely with blood glucose concentration in these patients. ${ }^{3}$ During the treatment of diabetic ketoacidosis the plasma magnesium concentration may fall severely such that magnesium supplements are required. ${ }^{4}$ Although our patient was not ketotic, her diabetes was undoubtedly poorly controlled. In addition, she was taking frusemide, and diuretics are known to induce hypomagnesaemia. ${ }^{5}$ This combination may have accounted for the severity of her hypomagnesaemia.

The neurological consequences of hypomagnesaemia range from muscular twitching to generalised seizures. Our patient presented with signs of a right sided parieto-occipital lesion and focal seizures refractory to conventional anticonvulsant treatment. These resolved completely on correction of her profound hypomagnesaemia. To our knowledge such focal seizures and neurological deficits have not been reported previously in association with hypomagnesaemia.

We suggest that the possibility of hypomagnesaemia be borne in mind when a diabetic presents with unexplained focal neurological signs. It may occur in the absence of other electrolyte disturbances and ketosis. Prompt replacement of this essential ion will lead to rapid resolution of the neurological deficit.

We thank Dr L C A Watson for permission to report on his patient.

1 Brenton DP, Gordon TE. Fluid and electrolyte disorders: magnesium. Br f Hosp Med 1984;32: 60-9.

2 Mather HM, Nisbet JA, Burton GH, et al. Hypomagnesaemia in diabetes. Clin Chim Acta 1979;95:235-42.

3 Yajnik CS, Smith RF, Hockaday TDR, Ward NI. Fasting plasma magnesium and glucose disposal in diabetes. $\mathrm{Br}$ Med $\mathcal{F} 1984 ; 288: 1032-4$.

4 Winter RJ, Harris CJ, Phillips LS, Green OC. Diabetic ketoacidosis. Induction of hypocalcemia and hypomagnesemia by phosphate therapy. Am J Med 1979;67:897-900.

5 Swales JD. Magnesium deficiency and diuretics. Br Med $\mathcal{F}$ 1982;285:1377-8.

(Accepted I September 1986)

Department of Medicine, University College Hospital, London WC1

FRANCIS MATTHEY, BSC, MRCP, medical registrar

C M GELDER, BSC, MB, house physician

F E G SCHON, PHD, MRCP, senior registrar in neurology

Correspondence to: Dr F Matthey, Academic Department of Haematology, Royal Free Hospital, London NW3 2QG.

\section{Mercury hazards arising from the repair of sphygmomanometers}

The symptoms of inorganic mercury poisoning are well described ${ }^{12}$; poisoning is known to have occurred in manufacturers of scientific instruments but not in people repairing sphygmomanometers. ${ }^{3}$ Early neuropsychiatric symptoms in one repairer led to the investigation of six sphygmomanometer workshops in Scotland.

\section{Case reports}

A 37 year old man worked for up to 60 hours a week for three years in a small, poorly ventilated room (volume roughly $140 \mathrm{~m}^{3}$ ) whose winter temperature sometimes exceeded $27^{\circ} \mathrm{C}$. He spent $5-10 \%$ of his time repairing sphygmomanometers containing mercury. He took refreshment and smoked cigarettes at his work. For a year he complained of worsening neuropsychiatric symptoms including tremor, forgetfulness, and irritability. His symptoms were initially attributed to overwork, until a 24 hour urine collection showed mercury concentrations of $200 \mathrm{nmol} / \mathrm{mmol}$ creatinine $(400 \mu \mathrm{g} / \mathrm{g})$. The upper $95 \mathrm{th}$ percentile for unexposed workers is less than $2 \mathrm{nmol} / \mathrm{mmol}$ creatinine $(4 \mu \mathrm{g} / \mathrm{g})$. Nerve conduction velocity and results of urine analysis and haematological, biochemical, ophthalmological examinations were normal. His symptoms improved as his urinary mercury concentration fell to more normal values, but he still complained of forgetfulness.

All subsequent urinary mercury concentrations in this patient and 20 other workers were determined using spot samples of early morning urine.

The index patient's 17 year old son developed a desquamating rash on his hands and forearms. His urinary mercury concentration was $91 \mathrm{nmol} / \mathrm{mmol}$ creatinine $(182 \mu \mathrm{g} / \mathrm{g})$. Acrodynia was diagnosed. Three workers working in the same premises as the index case were found to have urinary mercury concentrations of $12-70 \mathrm{nmol} / \mathrm{mmol}$ creatinine $(24-140 \mu \mathrm{g} / \mathrm{g})$. None had symptoms.

A visit to the premises showed contamination of work surfaces; when the floor and bench coverings were lifted many small globules of mercury were evident. Decontamination was tried, but six months afterwards an environmental survey carried out by an occupational hygienist (Wolfson Institute, Ninewells Hospital, Dundee) with a Baccarah mercury sniffer MV2 showed levels of mercury in air in the workshop to be six to 10 times the recommended limit $\left(0.05 \mathrm{mg} / \mathrm{m}^{3}\right)$. The highest levels were found near a chair in which the index patient sat.

Sixteen employees in five other sphygmomanometer workshops throughout Scotland produced specimens of urine with mercury concentrations of 2-139 $\mathrm{nmol} / \mathrm{mmol}$ creatinine $(4-278 \mu \mathrm{g} / \mathrm{g})$. The employee with the highest concentration had symptoms, but these were more probably attributable to alcohol. None of the others had symptoms.

Environmental monitoring in one of the workshops (four employees) by an 
occupational hygienist (field consultant group, Health and Safety Executive, Edinburgh), showed levels of mercury in the air to be between three to eight times the recommended limit. Advice was given about improving working practices in the three premises where raised concentrations of mercury in urine were found and in one where inadequate protection was provided, although no work had been done on sphygmomanometers for almost two months.

\section{Comment}

The urinary mercury concentrations in these workers indicated appreciable absorption. Our experience shows that the upper 95 th percentile for dental workers is $10 \mathrm{nmol} / \mathrm{mmol}$ creatinine $(20 \mu \mathrm{g} / \mathrm{g})$ and for industrial workers $70 \mathrm{nmol} / \mathrm{mmol}(140 \mu \mathrm{g} / \mathrm{g})$. Concentrations in excess of $120 \mathrm{nmol}$ $\mathrm{mmol}(240 \mu \mathrm{g} / \mathrm{g})$ are considered to be potentially dangerous. ${ }^{4}$

Sphygmomanometer workers handle fairly small amounts of mercury; there are 64-85 $\mathrm{g}$ in one instrument. Their exposure, however, is more direct than that of many other workers, and they are much less aware of the risks The working conditions in the premises fall short of those recommended, and two premises were so bad that the factory inspectorate prohibited work until the deficiencies had been remedied. At all the premises the workers' urinary mercury concentrations fell once the advice of the factory inspectorate had been acted on.

At a cautious estimate there are probably 10000 sphygmomanometers in Scotland. Unless they are serviced in a controlled working environment then those doing this work may be at risk. The hazard could be abolished if digital or aneroid sphygmomanometers were used instead.

I thank my colleagues in the Health and Safety Executive in Scotland for visiting workplaces, the Health and Safety Executive Occupational and Medicine Laboratories for making the urinary mercury measurements, and Dr W Gray for permission to report on patients under his care.

1 Hunter D. Diseases of occupation. London: Hodder and Stoughton, 1975:294.

2 Bidstrup P. Toxicology of mercury and its compounds. Amsterdam: Elsevier, 1964:37-59.

3 Chief Inspector of Factories. Annual report on industrial health (1960). London: HMSO, 1961: 26. (Cmmd 1478.)

4 Health and Safety Executive. Mercury-medical surveillance. London: HMSO, 1978. (Guidance note MS 12.

5 Health and Safety Executive. Mercury-health and safery precautions. London: HMSO, 1977. (Guidance note EH 17.)

(Accepted 8 September 1986

Employment Medical Advisory Service, Health and Safety Executive, Dundee DD1 1TX

CHRISTOPHER W IDE, MRCGP, AFOM, employment medical adviser

\section{The peak flow whistle: a simple device for monitoring peak flow in children}

We undertook a study to evaluate a cheap and simple device for estimating peak flow in children, the peak flow whistle.

\section{Subjects, methods, and results}

The peak flow whistle is a small cardboard cylinder with nine graduated holes along its side with a shorter outer cylinder that can be slid up and down to occlude some of the holes (Alternate Resources Ltd). A mouthpiece is fitted into one end and a whistle to the other. The air flow required to sound the whistle is proportional to the number of holes that are open, and the whistle can be sounded by either blowing or sucking through the mouthpiece. With one hole open a minimum flow of $60 \mathrm{l} / \mathrm{min}$ is required to sound the whistle, with two holes open the flow must be greater than $120 \mathrm{l} / \mathrm{min}$, and so on. The whistle can therefore be used to define a range of peak flow. The sensitivity was expanded by occluding half a hole to provide intermediate readings.

The device was evaluated by comparing its readings with those obtained with a Wright peak flow meter. Altogether 101 children ( 65 boys, 36 girls) aged $3-12$ were instructed to blow three times into a standard Wright peak flow meter and three times through the whistle. The peak flow meter was used first so that the whistle could be preset to a point where the child would be likely to sound it. The values obtained with the whistle and the peak flow meter were compared in 54 of the children, who produced a consistent peak flow-that is, less than $10 \%$ variation in peak flow measured with the peak flow meter.

The midpoint of the whistle's highest range of readings and the highest readings obtained with the Wright peak flow meter were compared by analysing the difference in peak flow and the average peak flow obtained with the two devices. ${ }^{1}$ The figure shows that the maximum peak flow recorded with the whistle was on average $30 \mathrm{~V} / \mathrm{min}$ less than that observed with the peak flow meter and the variation about the mean was stable over a wide range of peak expiratory flowD rates. The mean $(\mathrm{SD})$ peak expiratory flow rate recorded with the peak flow meter for each subgroup of children making the whistle sound at different holes was: one hole, 105 (26) $1 / \mathrm{min}$ (four children); two holes, 155 (26) $1 / \mathrm{min}$ (four); three holes, 230 (20) $\mathrm{l} / \mathrm{min}$ (13); four holes, 301 (29) $\mathrm{l} / \mathrm{min}$ (20); five holes, 344 (27) $\mathrm{l} / \mathrm{min}^{\mathrm{C}}$ (eight); six holes, 375 (28) $1 / \min$ (five).

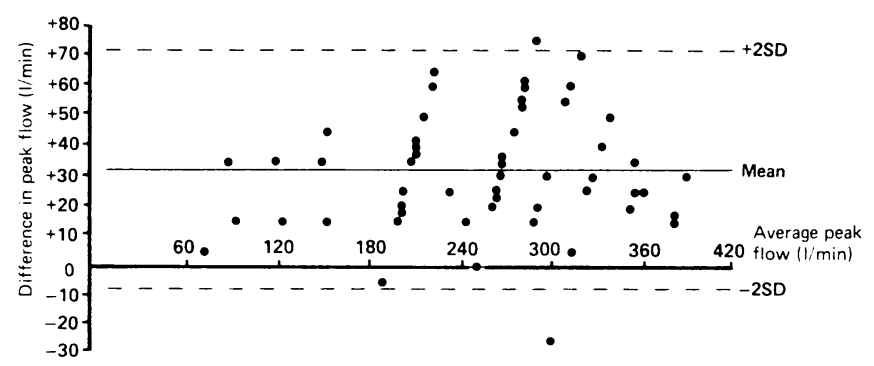

Difference in peak flow measured with Wright peak flow meter and peak flow $\overrightarrow{0}$ whistle plotted against average peak flow measured with the two devices in 54children.

\section{Comment}

Subjective perception of asthma varies, and many patients with asthmaw cannot detect deterioration in their lung function; thus measurement of peakio flow is desirable because it is an objective method of monitoring control of asthma. ${ }^{2}$ This is particularly important when patients are given home 6 nebulisers for the administration of $B_{2}$ agonists. ${ }^{3}$ Minimum peak flow values $\vec{A}$ can also be used to indicate when medical advice or admission to hospitale should be sought. Despite this only a small proportion of patients withou asthma have had their lung function measured. ${ }^{4}$

Our results show that the peak flow whistle performs similarly to the Wright peak flow meter. The mean readings obtained with the peak flowe meter for each whistle hole were within $5-30 \mathrm{l} / \mathrm{min}$ of the midpoint of nominal values for the adjacent holes. The whistle underestimated by $30 \mathrm{l} / \mathrm{min}$ on average the value that was obtained with the peak flow meter. We $\frac{\mathbb{D}}{3}$ found that in contrast to a similar device used in the past, the whistle can produce a clear whistle at least up to $420 \mathrm{l} / \mathrm{min} .{ }^{5}$ Additionally, getting the child to suck rather than blow through the device was useful in instructing him in the use of dry powder inhalers.

The peak flow whistle is a cheap, effective device. Its low cost (less than? one seventh of that of conventional mini peak flow meters) should enable selfo monitoring of patients with asthma to be greatly extended.

We thank Glaxo Pharmaceuticals for support.

I Bland JM, Altman DG. Statistical methods for assessing agreement between two methods of clinical measurement. Lancet 1986; ; $307-10$

2 Sly P, Landau L, Weymouth R. Home recording of peak expiratory flow rates and perception of asthma. Am $\mathcal{F}$ Dis Child 1985;139:479.82.

3 Laroche CM, Harries AVK, Newton RCF, et al. Domiciliary nebulisers in asthma: a district? survey. BrMed f 1985;290:1611-3.

4 Anderson H, Bailey P, Cooper J, Palmer J, West S. Medical care of asthma and wheezing illness in children: a community survey. I Epidemiol Community Health 1983;37:180-6. 5 Colley JRT, Holland WW. Evaluation of the de Bono whistle as a screening test of lung function.
Lancet 1965;ii:212-4.

(Accepted 9 September 1986)

Department of Paediatrics, University of Sheffield, Children's Hospital, Sheffield S10 2TH

J N TSANAKAS, MD, clinical research assistant

O M BANNISTER, MCSP, SRP, deputy superintendent physiotherapist

A W BOON, MD, MRCP, senior lecturer in paediatrics

R D G MILNER, MD, MRCP, professor of paediatrics

Correspondence to: Professor Milner.

\section{Correction}

Psychological impact of adjuvant chemotherapy in the first two years after mastectomy

We regret that an error occurred in this paper by Dr A V M Hughson and others (15 November, p 1268). The footnotes of tables III and IV should have read: $\overrightarrow{\mathbb{D}}$ "Fisher's exact test on combined data from groups who received chemotherapy and combined treatment because of small expected frequencies," and not, as< appeared in the journal, "groups who received radiotherapy and combined treatment." 